\title{
The effect of Non-Governmental Organizations (NGO)'s approaches on women's empowerment in Shiraz, Iran
}

\begin{abstract}
The paper attempts to determine the impact of Non-Government Organizations (NGO's) approaches on the empowerment of women in Shiraz, Iran. Through empowerment, women become able to organize themselves, to increase self-reliance and to assert their independent right to make choices and control resources. In this study, empowerment is conceptually defined and analyzed at two levels, that is, 'individual' and 'community'. The study based on 195 women participants in NGO's activities showed that their level of empowerment is moderate. This means they are neither disempowered nor empowered sufficiently. Various approaches were adopted by the local NGOs such as top-down, partnership and bottom-up to help women to achieve the empowerment. The result indicated the bottom-up approach is the most effective approach on the empowerment of women.
\end{abstract}

Keyword: Empowerment; Bottom-up; Partnership; Top-down; Non-Governmental Organizations; Iran 